Mohammadi, H., Nikjoyan, J. M., Hazrati, S., Hashempour, H. (2020): Improvement of yield and phytochemical compounds of Thymus vulgaris through foliar application of salicylic acid under water stress. Agriculture and Forestry, 66 (1): 129-142.

DOI: 10.17707/AgricultForest.66.1.13

\begin{abstract}
Hamid MOHAMMADI ${ }^{1 *}$, Mohammad JAVAD NIKJOYAN ${ }^{2}$, Saeid HAZRATI ${ }^{1}$, Hossein HASHEMPOUR ${ }^{3}$
\end{abstract}

\title{
IMPROVEMENT OF YIELD AND PHYTOCHEMICAL COMPOUNDS OF Thymus vulgaris THROUGH FOLIAR APPLICATION OF SALICYLIC ACID UNDER WATER STRESS
}

\begin{abstract}
SUMMARY
Thymus vulgaris is an important medicinal plant across the world that has been grown in Iran since ancient times. To study the effect of foliar application of salicylic acid (SA) on the yield and phytochemical compositions of T. vulgaris, an experiment was conducted in Qazvin in 2017. A factorial experiment based on a randomised complete block design was conducted with three replications. Treatments of SA (0, 100, 150 and $200 \mathrm{mg} / \mathrm{L})$ were applied from the period before flowering until the early stages of flowering under well-watered and withholding irrigation conditions. The results showed that SA had a significant effect on the yield and phytochemical compositions of $T$. vulgaris under both irrigation regimes. SA foliar application led to an increase in total dry matter. The highest total dry matter (1958.83 $\mathrm{kg} \mathrm{ha}^{-1}$ ) was obtained by applying $200 \mathrm{mg} / \mathrm{LSA}$ under normal irrigation. The effect of foliar application of SA on the essential oil content of $T$. vulgaris was influenced by the irrigation regime. The highest essential oil content (2.66\%) was obtained by applying a foliar spray of 100 mg/LSA under withholding irrigation conditions. Thymol, carvacrol, p-cymene, linalool and $\gamma$-terpinene were identified as the main essential oil compounds. The highest thymol content was obtained by foliar application of $200 \mathrm{mg} / \mathrm{LSA}$ under withholding irrigation conditions. Our results demonstrate that foliar application of SA reduced the negative effect of water deficit on $T$. vulgaris and increased yield and thymol content. SA foliar application is a simple, eco-friendly and relatively commercially viable method of increasing yield and the synthesis of phytochemicals; therefore, it may be used to improve the dry matter and quality of the essential oils of thyme plants.
\end{abstract}

Keywords: Dry matter, Essential oil, Stress, Thymus, Thymol.

\footnotetext{
${ }^{1}$ Hamid Mohammadi (corresponding author: hmohammadi@azaruniv.ac.ir), Faculty of Agriculture, Azarbaijan Shahid Madani University, Tabriz, IRAN.

2 Department of Genetics and Plant Breeding, Faculty of Agriculture and Natural Resources, Imam Khomeini International University, Qazvin, IRAN.

${ }^{3}$ Faculty of Basic Sciences, Azarbaijan Shahid Madani University, Tabriz, IRAN.

Notes: The authors declare that they have no conflicts of interest. Authorship Form signed online.

Received:01/11/2019

Accepted:15/12/2019
} 


\section{INTRODUCTION}

Thyme is one of the 8 most important members of the Lamiaceae family. More than 360 species of thyme grow in the world, and one of the most important species that commonly cultivated in the world is Thymus vulgaris (Lawrence and Tucker., 2002; Zarzuelo and Crespo., 2002). Annual global production for dry matter and essential oils from thyme are estimated around 1500 and 30 tons, respectively. Mediterranean with a value of US\$ 1.5 million is the main region of production thyme products. Thyme cultivation area in Iran has been reported to be 50 ha with the estimated annual production of 270 tons per year (MAJ., 2015; McGimpsey., 1993)

T. vulgaris is one of the medicinal plants, native to southern Europe, and has a worldwide distribution (Hosseinzadeh et al., 2015), and in addition to higher quantity and quality of essential oils (higher percentage of essential oil and thymol and carvacrol compared to other species), it also has a relatively widespread distribution in the world, which shows the adaptation and tolerance of the plant to different environmental conditions. This plant's valuable essential oils are of great importance in the pharmaceutical, cosmetic and perfumery industries, and also in preparation of spices (Nickavar et al., 2005).

T. vulgaris, genetically, morphologically and phytochemically has a very high diversity (Nielsen et al., 2017). Phytochemical constituents of thyme mainly consist of monoterpene, sesquiterpene and phenolic compounds (Hosseini et al., 2015; Ebadollahi., 2018). Previous research shows that essential oil compositions in thyme mainly consist of thymol, carvacrol, p-cymene and c-terpinene, and their quantity changes when affected by environmental stresses (Khalil et al., 2018; Mohammadi et al., 2019).

Therefore, achieving the best culture environment by enhancing the performance and active components is one of the most important purposes in the cultivation of medicinal plants (Jaafar et al., 2012). Drought as one of the most important abiotic stresses, and it is a very serious threat to the agricultural industry worldwide, which usually reduces growth, yield and also causes physiological and phytochemical changes (Karim et al., 2015). Improving the drought tolerance is one of the proposed methods to cope with the drought problem that it complies with economic demands, so that plants have the minimum need for water and maximum production in a drought condition. Due to some secondary metabolites and morphological characteristics, medicinal plants have the potential to withstand more stress compared to other plants and they are a suitable choice for cultivation under stressful conditions (Akula and Ravishankar., 2011; Isah., 2019).

One of the most important techniques to increase the rate of accumulation of phytochemicals compounds such as percentage and constituents of essential oils is the use of growth regulators under drought stress (Yucel Candan and Heybet Elif., 2016; Khalil et al., 2018).

External usage of growth regulators has been studied as a method to reduce the negative effects of drought stress and increase the plant compatibility (Khan 
et al., 2015; Abbaspour and Babaee., 2017). Salicylic acid or orthohydroxy benzoic acid is one group of the plant growth regulators which is available throughout the plant dynasty. This growth regulator belong to a diverse group of plant phenols which has an aromatic ring with a hydroxyl group and is effective on many physiological processes of plants (Tripathi et al., 2019). The effects of SA and its key roles in the regulation of different physiological processes of the plant have been examined in various studies (Belt et al., 2017).

Given that SA plays an important role in plant growth and increasing performance, recently the use of SA has been increased in raising the resistance of the plant against biotic and abiotic stresses (Sawada et al., 2006; Rivas-San Vicente and Plasencia., 2011; Liu et al., 2015; Shahmoradi and Naderi., 2018). Many reports have shown that SA at low concentrations usually increases photosynthesis (Stevens et al., 2006), uptake and transfer of nutrients, photosynthetic pigments (Mohammadi et al., 2019), activity of antioxidant enzymes (Ananieva et al., 2004; Alam et al., 2013; Habibi., 2017), phytochemicals compounds especially phenolic compounds (Khan et al. 2015; Khalil et al., 2018), essential oil content (Kovácik et al., 2009; Khalil et al., 2018), tolerance to oxidative stress and decreases osmotic stress (Nazar et al., 2011), results of these studies suggest that exogenously applied SA can reduce drought stress impact on plants.

The effects of foliar application of SA, to a great extent, depends on genetics and the environmental factors (Idrees et al., 2011), and also on the applied method and concentration level (Horváth et al., 2007). Some studies show that foliar application of SA has an impact on effective compounds especially the percentage and composition of essential oils of oleoresins in Pinus elliottii (Rodrigues and Fett-Neto., 2009), triterpenes in Nigella sativa (Elyasi et al., 2016), Ocimum basilicum L. (Mirzajani et al., 2015), and Rosemary (El-Esawi et al., 2017).

The purpose of the present study was to evaluate the effect of foliar application of SA on the improvement of yield and the phytochemical constituents of $\mathrm{T}$. vulgaris under water stress.

\section{MATERIAL AND METHODS}

The experiment was conducted at the research field of Qazvin, Iran, during 2017. The factorial experiment was conducted in the frame of randomized complete block design with three replications. The first factor was the irrigation regimes (well-watered and withholding irrigation) and the second factor was the foliar application of salicylic acid (0, 100, 150 and $200 \mathrm{mg} / \mathrm{L}$ ).

The application of the treatments was before flowering until early stages of flowering at 70 days after transplanting seedlings into the field. The soil moisture content of all plants was maintained at the field capacity (FC) level before starting the withholding irrigation treatment. From pre-flowering phase until early stage of flowering (when $50 \%$ of the plants entered this stage), withholding irrigation was applied, while well-watered plants were irrigated to $80 \%$ of field capacity. The 
moisture content of the soil was measured in each plot using TRIME-TDR (Bahreininejad et al., 2013; Mohammadi et al., 2019). From this point on, water stressed plants were no longer irrigated, while well-watered plants were further irrigated until the early stages of flowering. A total of three sprays of SA were carried out. SA was applied using a hand sprayer until the solution began to drip off leaves at sunset. The plots not receiving SA was treated similarly with equivalent amount of distilled water.

The seeds of the $T$. vulgaris German cultivar 'Deutscher Winter was purchased from a Pakan Seed Company, Isfahan, Iran. The seeds were planted into plastic pots $(20 \mathrm{~cm}$ in length and $25 \mathrm{~cm}$ in diameter), which were filled with sandy loam soil, pH: 7.2, and kept under light/dark cycle conditions of 16/8 h maintained at $23{ }^{\circ} \mathrm{C}$ and $73 \%$ relative humidity placed in a greenhouse. Then, when seedlings reach a height of $12-15 \mathrm{~cm}$, they are transplanted to a field. Each experimental plot had three rows with $3 \mathrm{~m}$ length and $50 \mathrm{~cm}$ distance between rows and $30 \mathrm{~cm}$ the distance of seedlings on the planting rows. Results of the physical and chemical analysis of the field soil (0-30 cm depth) described in Table 1 . The plant shoots were removed from each treatment at $50 \%$ flowering stage, Harvested tissues were weighed and dried at $40{ }^{\circ} \mathrm{C}$ in a forced air oven for 48h.Plant dry weight, and total phenol and essential oil were extracted and measured.

Table 1. Physical and Chemical analysis of the field soil (0-30 cm depth).

\begin{tabular}{|c|c|c|c|c|c|c|c|c|c|}
\hline $\begin{array}{c}\mathrm{EC} \\
\left(\mathrm{dSm}^{-1}\right)\end{array}$ & $\mathrm{pH}$ & $\begin{array}{c}\text { Organic } \\
\text { matter } \\
(\%)\end{array}$ & $\begin{array}{c}\text { Nitrogen } \\
(\%)\end{array}$ & $\begin{array}{c}\mathrm{K} \\
(\mathrm{mg} / \mathrm{kg})\end{array}$ & $\begin{array}{c}\mathrm{P} \\
(\mathrm{mg} / \mathrm{kg})\end{array}$ & Texture & $\begin{array}{c}\text { Sand } \\
(\%)\end{array}$ & $\begin{array}{c}\text { Loam } \\
(\%)\end{array}$ & $\begin{array}{c}\text { Clay } \\
(\%)\end{array}$ \\
\hline 2.12 & 7.2 & 0.61 & 0.07 & 139 & 12.2 & Loam & 32 & 38 & 30 \\
\hline
\end{tabular}

\section{Total phenols content}

Folin-Ciocalteu reagent is used to estimate the total phenols. First, exactly $0.5 \mathrm{~g}$ of the sample is grinded in 10-time volume of $80 \%$ ethanol by a pestle and mortar. Then, the homogenate is centrifuged at 10,000 rpm for 20 min and the supernatant is collected. The residue is then re-extracted with five times the volume of $80 \%$ ethanol. In the next step, the supernatant is centrifuged and dried by evaporating. The residue is dissolved in a certain volume of distilled water ( 5 $\mathrm{ml}$ ). Then, different volumes ( 0.2 to $2 \mathrm{ml}$ ) of residue are combined with water in the test tubes. The volume of the resultant mixture in each tube should be $3 \mathrm{ml}$. Next, $0.5 \mathrm{ml}$ of Folin-Ciocalteu reagent is added to the mixture. After $3 \mathrm{~min}, 2 \mathrm{ml}$ of $20 \% \mathrm{Na} 2 \mathrm{CO} 3$ solution is added to each tube and the mixture is mixed rapidly. Then the tubes are placed in the boiling water for exactly one min. The absorbance is measured at $725 \mathrm{~nm}$ against a reagent blank after cooling the mixture. Finally, different concentrations of Gallic acid are used to prepare a standard curve (McDonald et al., 2001). 


\section{Measuring the yield of essential oil}

The aerial parts of each treatment were dried immediately at room temperature in shade, and then the yields ( $\mathrm{w} / \mathrm{w} \%$ ) of oils were determined by using of Clevenger Apparatus. The essential oil extraction time was the same for all samples as 2-3 h. The essential oil was dried by anhydrous sodium sulfate, then weight of the pure essential oil was determined, and its value was calculated according to its weight to the dry weight of the plant sample (w/w \%). Finally, the obtained essential oils kept in dark sealed vials at $4{ }^{\circ} \mathrm{C}$ until analysis.

Identifying essential oil compounds

GC-FID analyses of the available compounds in essential oil were carried out using a Thermoquest-Finnigan instrument. The analyses were performed on DB-5 fused silica capillary column $(30 \mathrm{~m} \times 0.25 \mathrm{~mm}$ i.d., film thickness 0.25 $\mu \mathrm{m})$. The carrier gas was nitrogen at a constant flow rate of $1.1 \mathrm{~mL}$ per min. The oven temperature program was set 60 (the initial temperature of the oven)-250 ${ }^{\circ} \mathrm{C}$ at the rate of $5^{\circ} \mathrm{C} / \mathrm{min}$ and held isothermally for $10 \mathrm{~min}$ at the final. The injector and detector (FID) temperature were set at $250{ }^{\circ} \mathrm{C}$ and $280{ }^{\circ} \mathrm{C}$. The split ratio was set at 100:1. GC-MS analyses were performed on Thermoquest-Finnigan Trace GC-MS instrument equipped with the same gas chromatography condition as mentioned for GC. The carrier gas was helium at the flow rate of $1.1 \mathrm{~mL}$ per min with the split ratio at 100:1. The transfer line and ion source temperature were set at $200{ }^{\circ} \mathrm{C}$ and $250{ }^{\circ} \mathrm{C}$, respectively. There was a mass spectrometer with $70 \mathrm{eV}$ ionization supply voltage.

Statistical analysis

The collected data were analyzed using SAS 9.1 software. The mean interactions were also compared through the Student-Newman-Keuls test at $5 \%$ level using MSTATC software.

\section{Total dry matter}

\section{RESULTS AND DISCUSSION}

Based on the results of analysis of variance (ANOVA) showed that the interaction effect of irrigation regimes and foliar applications of salicylic acid has significant effect on a dry matter of the foliage (Table 2). Results of mean comparisons are presented in Figure 1. The results showed that the highest amount of dry matter was obtained, in the normal irrigation conditions and foliar application of $200 \mathrm{mg} / \mathrm{L} \mathrm{SA}$, that increased by $25 \%$ compared with, under withholding irrigation conditions and without foliar application of SA (Figure 1). Exogenous SA application significantly increased dry matter in both irrigation regimes.

Increment in dry matter is probably due to increased stabilization of $\mathrm{CO} 2$ by exogenous SA application, which in different physiological processes, such as the increase in photosynthetic pigments, promote Rubisco activity, it is ultimately providing more ATP and NADPH and stabilizing carbon and producing more assimilate (Athar and Ashraf, 2005; Lawlor and Cornic, 2002). 
Table 2. Analysis of variance (ANOVA) of the effect of salicylic acid and irrigations regimes on Thymus vulgaris

\begin{tabular}{|c|c|c|c|c|c|}
\hline \multirow[t]{2}{*}{ Traits } & \multicolumn{5}{|c|}{ Mean squares for source of variation } \\
\hline & Block & $\begin{array}{l}\text { Factor a } \\
\text { (irrigation } \\
\text { regimes) }\end{array}$ & $\begin{array}{l}\text { Factor b } \\
\text { (application } \\
\text { of salicylic } \\
\text { acid) }\end{array}$ & $\begin{array}{l}\text { Interactio } \\
\mathrm{n} \mathrm{a} \times \mathrm{b}\end{array}$ & Error \\
\hline d.f & 2 & 1 & 3 & 3 & 10 \\
\hline Total DM & $2097.55^{\mathrm{ns}}$ & $254018.95^{* *}$ & $74772.84^{* *}$ & $4987.10^{*}$ & 1029.31 \\
\hline $\begin{array}{l}\text { Essential oil } \\
\text { yield }\end{array}$ & $0.0017^{\mathrm{ns}}$ & $1.05^{* *}$ & $0.07^{* *}$ & $0.03^{* *}$ & 0.001 \\
\hline Total Phenol & $0.08^{\mathrm{ns}}$ & $287.22^{* *}$ & $18.27^{* *}$ & $7.23^{* *}$ & 0.28 \\
\hline
\end{tabular}

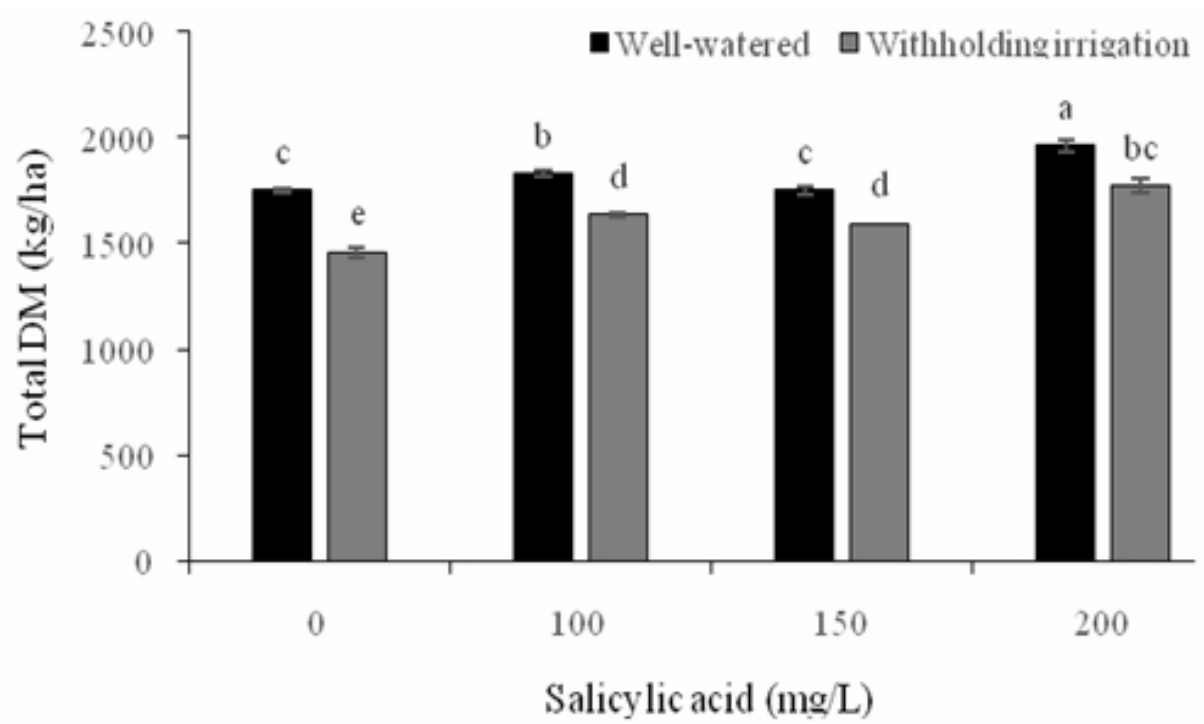

Figure 1: The effects of exogenous application of salicylic acid on total DM of Thymus vulgaris under water stress conditions.

Given that SA facilitates absorption of nutrients, it has a positive role in photosynthesis and photosynthetic enzymes, therefore it was expected that plants treated with salicylic acid lead to higher dry matter whether under stress condition or non-stress condition. The increase of dry matter with foliar application of SA under abiotic stress was reported on barley (Habibi., 2011), fennel (Askari and Ehsanzadeh., 2015), Thymus kotschyanus and Thymus vulgaris (Khalil et al., 2018; Mohammadi et al., 2019). The increase in dry mass of water-stressed plants in response to SA may be associated to the induction of antioxidant responses that protect the plant from stress damage (Singh and Usha., 
2003). It is also reported that salicylic acid increases the amount of lignin in the cell wall structure, which can be a factor in increasing plant biomass weight (Hayat et al., 2010). The ability of SA to increase plant dry mass, negating the adverse effects of withholding irrigation, may have significant contributions in improving plant growth and overcoming the yield barrier arising from conditions of limited water availability.

\section{Essential oil content}

The results of analysis of ANOVA showed that the interaction effect of irrigation regime and foliar application of SA has a significant effect on content of the essential oil of the leaves (Table 2). According to the results, the highest content of essential oil (2.66\%) was obtained in withholding irrigation and foliar application of $100 \mathrm{mg} / \mathrm{LSA}$, and the lowest content (2.003\%) was obtained in non-water stress condition and foliar application of SA, but no differences were observed between SA concentrations (Figure 2). The content of essential oil was higher under withholding irrigation condition compared to non-stress conditions.

-Well-watered $\square$ Withholdingirrigation

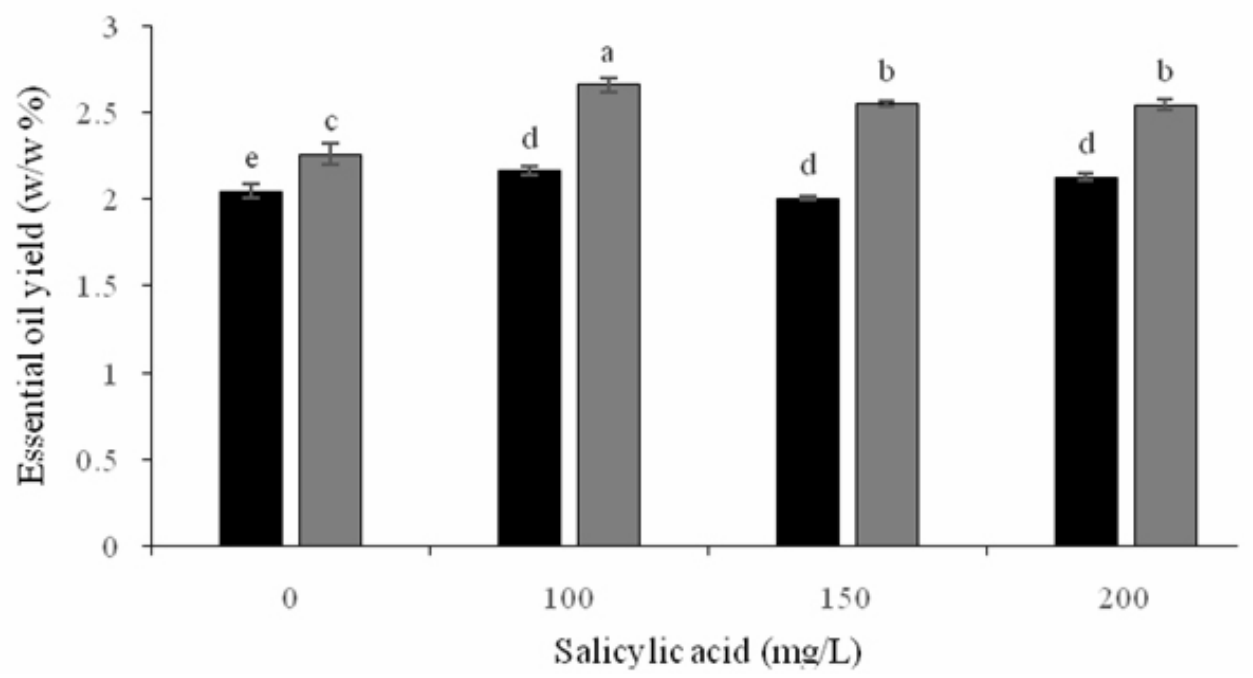

Figure 2: The effects of exogenous application of salicylic acid on essential oil yield of Thymus vulgaris under water stress conditions

The increase in essential oil content of the thyme leaves under the withholding irrigation was reported by Simon et al. (1992). The essential oil accumulation by withholding irrigation act as a defense mechanism and it is also because of the increase in the number of glands in the leaves (Simon et al., 1992). Our results indicate, essential oil content increased with increasing SA concentration and water deficit severity. Increase in content of essential oil by foliar application of SA can be due to increased nutrient absorption, increased number of glands of essential oil accumulation, increased synthesis of 
monoterpenes, that was conducted in previous studies on T. vulgaris (Khalilet al., 2018; Mohammadi et al., 2019) basil and marjoram (Gharib, 2007) and Mentha piperita (Saharkhiz and Goudarzi, 2014). In general, in the present experiment, the highest percentage of essential oil was obtained under withholding irrigation and foliar application of $100 \mathrm{mg} / \mathrm{L} \mathrm{SA}$. This achievement might be important from economically point of view for thyme essential oil production.

\section{Content of total phenol}

The results of ANOVA indicated that interaction effect of irrigation regimes and foliar application with SA had a significant impact on total phenol content (Table 2). The highest total phenol content of $18.431 \mathrm{mg} \mathrm{GAE} / \mathrm{g}$ DW was observed under withholding irrigation and $200 \mathrm{mg} / \mathrm{LSA}$ foliar application which was $58 \%$ higher than the control treatment (Figure 3 ).

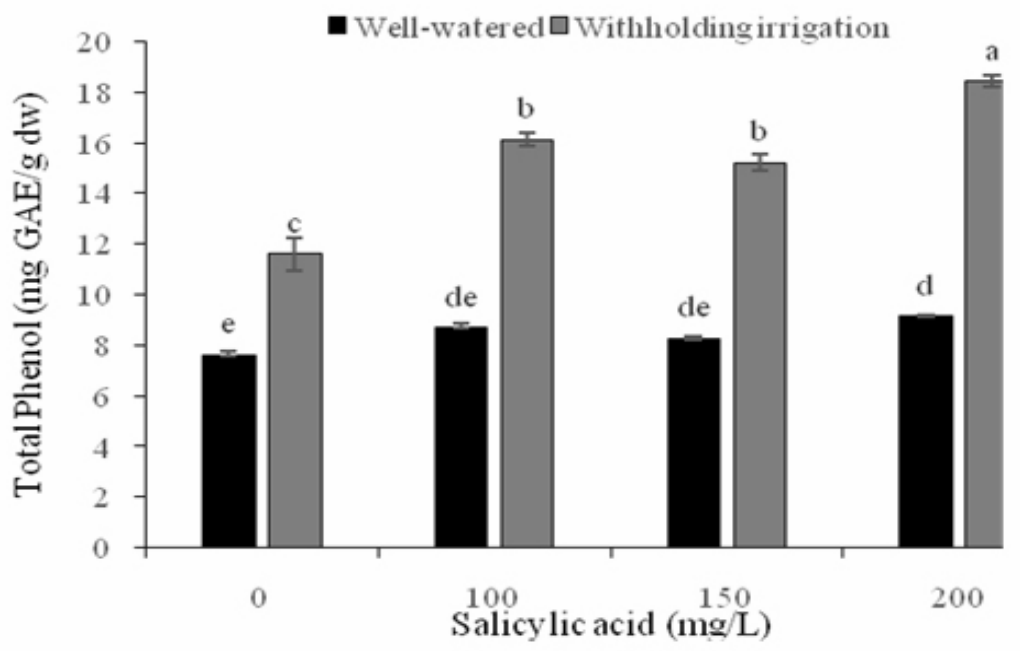

Figure 3: The effects of exogenous application of salicylic acid on total phenol of Thymus vulgaris under water stress conditions.

Phenolic compounds are an important group of secondary metabolites in medicinal plants that act as an antioxidant under environmental stress and its quantity usually increases in most plants (Agati and Tattini, 2010).The results of this experiment showed that withholding irrigation increased the amount of phenolic content. However, this increase was greater with SA foliar application. Similar results were reported by Khalil et al. (2018) on T. vulgaris.

In order to cope against withholding irrigation, plants increase the synthesis of secondary metabolites like phenol, which have an antioxidant role. $\mathrm{SA}$ is known to potentially generate a wide array of metabolic responses in plants, and affect a range of plant functions, including plant phenol content (Hayat et al., 2010). An increased synthesis of this compound in SA was also reported by other researchers (Dihazi et al., 2003; Mendoza et al., 2018; Mohammadi et al., 2019). Increase in total phenol occurs by inducing 
Phenylalanine ammonia-lyase enzyme and Tyrosine ammonia-lyase which are key enzymes in the synthesis of this compound in salicylic acid (Beaudoin-Eagan and Thorpe, 1985).

\section{Essential oil constituents}

According to the results of GC-MS analysis, 14 compounds were identified. The main constituents included thymol, $\gamma$-terpinene, carvacrol, geranial, $\rho$-cymene (Table 3). Foliar application of SA and withholding irrigation conditions resulted in a significant increase in the amount of thymol compound at both irrigation levels. The highest amount of thymol was observed in withholding irrigation condition with foliar application of $200 \mathrm{mg} / \mathrm{LSA}$, and the lowest amount was observed in the normal irrigation and without SA application (Table 3).

Foliar application of SA and withholding irrigation decreased the amount of $\gamma$-terpinene compound. The highest amount of this compound was obtained as $16.11 \%$ in non-water stress without foliar application of SA. In non-stress condition, foliar application of SA increased the $\rho$-cymene compound, but under withholding irrigation condition, foliar application of SA decreased content. The highest amount of $\alpha$-terpineol was obtained by the foliar application of 150 $\mathrm{mg} / \mathrm{LSA}$ and under non-stress conditions, but under withholding irrigation it was obtained by $200 \mathrm{mg} / \mathrm{L}$ foliar application. Also, SA foliar application significantly increased this compound under normal conditions. The highest value was obtained as $5.79 \%$ in the foliar application of $150 \mathrm{mg} / \mathrm{LSA}$.

The result indicated that main constituents included thymol, $\gamma$-terpinene, carvacrol, geranial, $\rho$-cymene (Table 3 ). There have already been numerous reports that the main constituents in the Thyme plants are thymol, p-cymene, carvacrol, and $\beta$-caryophyllene (Dehghani Mashkani et al., 2018; Mohammadi et al., 2019).

The results indicated that there is a variation in essential oil compounds in the studied treatments. Thymol was the most abundant compound detected in essential oil. Thymol content increased with increasing SA concentration and water deficit stress. In previous studies increase in thymol amount has been reported under water deficit stress (Bahreininejad et al., 2014; Askary et al., 2018; Mohammadi et al., 2019).

A decrease of $\gamma$-terpinene was reported with withholding irrigation and foliar application of SA on T. vulgaris (Khalil et al., 2018).

The carvacrol significantly decreased under withholding irrigation condition, which other researchers have found similar results on $T$. vulgaris (Letchamo et al., 1995) and T. hyemalis (Aziz et al., 2008). The essential oil compounds had different reactions to withholding irrigation and foliar application of SA. So that foliar application of SA with a high concentration of $200 \mathrm{mg} / \mathrm{L}$ led to a significant increase in the compound of oxygenated monoterpenes. Almost all the compounds obtained from this treatment that was at value of 99.92 in this group. 


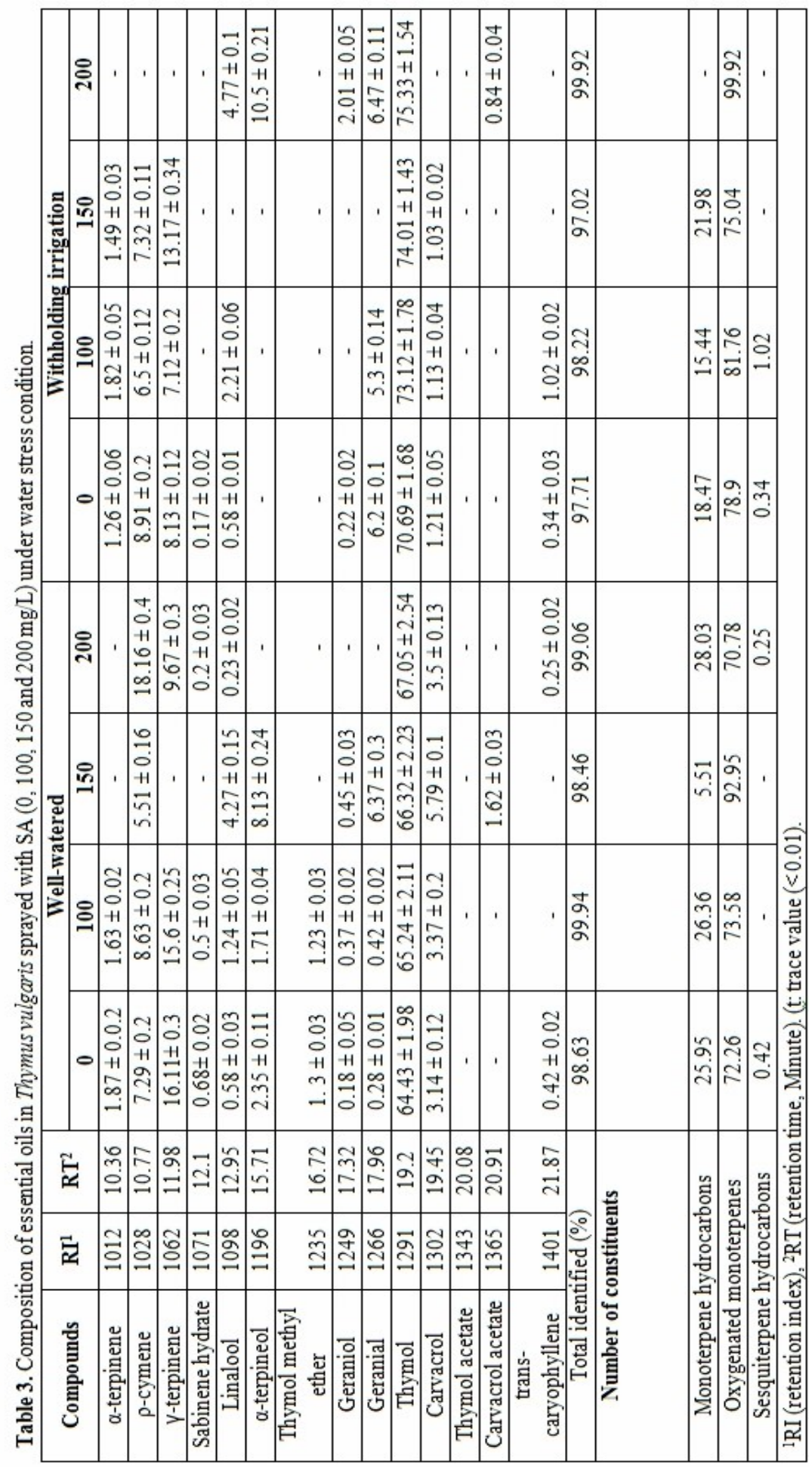




\section{CONCLUSIONS}

Foliar application of SA at moderate concentrations increased dry matter yield, essential oil content and some essential oil compounds of Thymus vulgaris the foliage under withholding irrigation conditions. Foliar application of SA (100 $\mathrm{mg} / \mathrm{L}$ ) increased dry matter yield and essential oil content under withholding irrigation, application $200 \mathrm{mg} / \mathrm{L} \mathrm{SA}$, increased the most important essential oil compounds involving thymol. Overall, the present study revealed that exogenous SA application could overcome the adverse effects of withholding irrigation by further accumulation of phytochemical composition, acting as osmotic and metabolic regulators or substrates and in a part as cell component stabilizers. In general, it can be mentioned that the application of low and highest concentrations of SA improves yield and its high concentration increases some active compounds in T. vulgaris.

\section{ACKNOWLEDGEMENTS}

The authors would like to thank Azarbaijan Shahid Madani University, Tabriz for conducting and financial support of this research.

\section{REFERENCES}

Abbaspour N, Babaee L. 2017. Effect of salicylic acid application on oxidative damage and antioxidant activity of Grape (Vitis vinifera L.) under drought stress condition. International Journal of Horticultural Science and Technology, 4(1):29-50.

Ananieva EA, Christov KN, Popova LP. 2004. Exogenous treatment with salicylic acid leads to increased antioxidant capacity in leaves of barley plants exposed to paraquat. Journal of Plant Physiology, 161(3):319-328.

Agati G, Tattini M. 2010. Multiple functional roles of flavonoids in photoprotection. New Phytologist, 156:786-793.

Akula R, Ravishankar GA. 2011. Influence of abiotic stress signals on secondary metabolites in plants. Plant Signaling \&Behavior, 6(11):1720-1731.

Alam MM, Hasanuzzaman M, Nahar K, Fujita M. 2013. Exogenous salicylic acid ameliorates short-term drought stress in mustard (Brassica juncea L.) seedlings by up-regulating the antioxidant defense and glyoxalase system. Australian Journal of Crop Science, 7:1053-1063.

Askari E, Ehsanzadeh P. 2015. Effectiveness of exogenous salicylic acid on root and shoot growth attributes, productivity, and water use efficiency of water-deprived fennel genotypes. Horticulture, Environment, and Biotechnology, 56(5): 687-696.

Askary M, Behdani MA, Parsa S, Mahmoodi S, Jamialahmadi M. 2018. Water stress and manure applications affect the quantity and quality of essential oil of Thymus daenensis and Thymus vulgaris. Industrial Crops and Products, 111:336-344.

Athar H, Ashraf M. 2005. Photosynthesis under drought stress. In: Hand Book of Photosynthesis, 2nd (Ed.) by M. Pessarakli. C.R.C. Press, New York, USA, pp. 795-8109.

Bahreininejad B, Razmjoo J, Mirza M. 2013.Influence of water stress on morphophysiological and phytochemical traits in Thymus daenensis. International Journal of Plant Production, 7(1):151-166. 
Beaudoin-Eagan LD, Thorpe TA. 1985. Tyrosine and phenylalanine ammonia lyase activities during shoot initiation in tobacco callus cultures. Plant Physiology, 78:438-441.

Belt K, Huang S, Thatcher LF, Casarotto H, Singh KB, Van Aken O, Millar AH. 2017. Salicylic acid-dependent plant stress signaling via mitochondrial succinate dehydrogenase. Plant Physiology, 173:2029-2040.

Dihazi A, Jaiti F, Zouine J, El Hassni M, El Hadrami I. 2003. Effect of salicylic acid on phenolic compounds related to date palm resistance to Fusarium oxysporum f. sp. albedinis. Phytopathologia Mediterranea, 42(1):9-16.

Ebadollahi, A. 2018. The essential oil extracted from Thymus kotschyanus Boiss. \& Hohen as a natural substance for management of the lesser grain borer, Rhyzopertha dominica F. Agriculture and Forestry, 64 (4): 49-55.

El-Esawi MA, Elansary HO, El-Shanhorey NA, Abdel-Hamid AME, Ali HM, Elshikh MS. 2017. Salicylic acid-regulated antioxidant mechanisms and gene expression enhance rosemary performance under saline conditions. Frontiers in Physiology, 8:716.

Elyasi R, Majdi M, Bahramnejad B, Mirzaghaderi G. 2016. Spatial modulation and abiotic elicitors responses of the biosynthesis related genes of mono/triterpenes in black cumin (Nigella sativa). Industrial Crops and Products, 79:240-247.

Gharib FAL. 2007. Effect of salicylic acid on the growth, metabolic activities and oil content of basil and majoram. International Journal of Agricultural and Biological, 9:294-301.

Habibi G. 2012. Exogenous salicylic acid alleviates oxidative damage of barley plants under drought stress. Acta Biologica Szegediensis, 56:57-63.

Habibi, G. 2017. Impact of salicylic acid on phenolic metabolism and antioxidant activity in four Grape cultivars during cold storage. International Journal of Horticultural Science and Technology, 4(2):217-228.

Hayat Q, Hayat S, Irfan M, Ahmad A. 2010. Effect of exogenous salicylic acid under changing environment: a review. Environmental and Experimental Botany, 68:1425.

Hosseinzadeh S, Jafari kukhdan A, Hosseini A, Armand R. 2015. The Application of Medicinal Plants in Traditional and Modern Medicine: A Review of Thymus vulgaris. International Journal of Clinical Medicine, 06(09):635-642.

Hosseini A, Armand R. 2015. The application of Thymus vulgaris in traditional and modern medicine: a review. Global Journal of Pharmacology, 9(3):260-266.

Horváth E, Szalai G, Janda T. 2007. Induction of abiotic stress tolerance by salicylic acid signaling. Journal of Plant Growth Regulation, 26(3):290-300.

Idrees M, Naeem M, Aftab T, Khan MMA. 2011. Salicylic acid mitigates salinity stress by improving antioxidant defense system and enhances vincristine and vinblastine alkaloids production in periwinkle [Catharanthus roseus (L.) G. Don]. Acta Physiologiae Plantarum, 33(3):987-999.

Isah T. 2019. Stress and defense responses in plant secondary metabolites production. Biological Research, 52(1):39.

Lawlor DW, Cornic G. 2002. Photosynthetic carbon assimilation and associated metabolism in relation to water deficits in higher plants. Plant Cell Environ, 25:275-294. 
Jaafar HZE, Ibrahim MH, Fakri NFM. 2012. Impact of soil field water capacity on secondary metabolites, phenylalanine ammonia-lyase (PAL), maliondialdehyde (MDA) and photosynthetic responses of Malaysian kacipfatimah (Labisia pumila). Molecules, 17:7305-7322.

Karim MR, Rahman MA. 2015. Drought risk management for increased cereal production in Asian Least Developed Countries. Weather and Climate Extremes, 7:24-35.

Khalil N, Fekry M, Bishr M, El-Zalabani S, Salama O. 2018. Foliar spraying of salicylic acid induced accumulation of phenolics, increased radical scavenging activity and modified the composition of the essential oil of water stressed Thymus vulgaris L. Plant Physiology and Biochemistry, 123:65-74.

Khan MIR, Fatma M, Per TS, Anjum NA, Khan NA. 2015. Salicylic acid induced abiotic stress tolerance and underlying mechanisms in plants. Frontiers in Plant Science, 6:1-17.

Kovácik J, Grúz J, Backor M, Strnad M, Repcák M. 2009. Salicylic acid-induced changes to growth and phenolic metabolism in Matricaria chamomilla plants. Plant Cell Reports, 28:135-143.

Lawrence BM, Tucker AO. 2002. The genus Thymus as a source of commercial products. Thyme, the genus Thymus. Taylor \& Francis, London, pp. 252-262.

Letchamo W, Xu HL, Gosselin A. 1995. Photosynthetic potential of Thymus vulgaris selections under two light regimes and three soil water levels. Scientia Horticulturae, 62(1-2):89-101.

Liu X, Rockett KS, Korner CJ, Pajerowska-Mukhtar KM. 2015. Salicylic acid signaling: new insights and prospects at a quarter-century milestone. Essays Biochem, 58:101-113.

Mashkani MRD, Larijani K, Mehrafarin A, Badi HN. 2018. Changes in the essential oil content and composition of Thymus daenensis Celak. under different drying methods. Industrial Crops and Products, 112:389-395.

McDonald S, Prenzler PD, Autolovich M, Robard S. 2001. Phenolic content and antioxidant activity of olive extracts. Food and Chemical Toxicology, 73:73-84.

Mirzajani Z, Hadavi E, Kashi A. 2015. Changes in the essential oil content and selected traits of sweet basil (Ocimum basilicum L.) as induced by foliar sprays of citric acid and salicylic acid. Industrial Crops and Products, 76: 269-274.

Ministry of Agriculture Jihad (MAJ). 2015. Communications and information technology center. Available at Web site http://amar.maj.ir/ Portal/Home/Default.aspx?

Mendoza D, Cuaspud O, Arias JP, Ruiz O, Arias M. 2018. Effect of salicylic acid and methyl jasmonate in the production of phenolic compounds in plant cell suspension cultures of Thevetia peruviana. Biotechnology Reports, 19: p.e00273.

McGimpsey J. 1993. Thyme-Thymus vulgaris. http://www.crop.cri.n2/broadshe/thyme.htm.

Mohammadi H, Amirikia F, Ghorbanpour M, Fatehi F, Hashempour H. 2019. Salicylic acid induced changes in physiological traits and essential oil constituents in different ecotypes of Thymus kotschyanus and Thymus vulgaris under wellwatered and water stress conditions. Industrial Crops and Products, 129:561-574.

Nazar R, Iqbal N, Syeed S, Khan NA. 2011. Salicylic acid alleviates decreases in photosynthesis under salt stress by enhancing nitrogen and sulfur assimilation and antioxidant metabolism differentially in two mung bean cultivars. Journal of Plant Physiology, 168:807-815. 
Nickavar B, Mojab F, Dolat-Abadi R. 2005. Analysis of the essential oils of two Thymus species from Iran. Food Chemistry, 90:609-611.

Nielsen JA, Grøndahl E, Callaway RM, Dickinson KJ, Ehlers BK. 2017. Home and away: biogeographical comparison of species diversity in Thymus vulgaris communities. Biological Invasions, 19(9):2533-2542.

Rivas-San Vicente M, Plasencia J. 2011. Salicylic acid beyond defense: its role in plant growth and development. Journal of Experimental Botany, 62:3321-3338.

Rodrigues KCS, Fett-Neto AG. 2009. Oleoresin yield of Pinus elliottii in a subtropical climate: seasonal variation and effect of auxin and salicylic acid-based stimulant paste. Industrial Crops and Products, 30:316-320.

Saharkhiz MJ, Goudarzi T. 2014. Foliar application of salicylic acid changes essential oil content and chemical compositions of peppermint (Mentha piperita L). Journal of Essential Oil Bearing Plants, 17(3):435-440.

Sawada H, Shim IS, Usui K. 2006. Induction of benzoic acid 2-hydroxylase and salicylic acid biosynthesis-Modulation by salt stress in rice seedlings. Plant Science, 2:263270.

Shahmoradi H, Naderi D. 2018. Improving effects of salicylic acid on morphological, physiological and biochemical responses of salt-imposed winter jasmine. International Journal of Horticultural Science and Technology, 5(2):219-230.

Singh B, Usha K. 2003. Salicylic acid induced physiological and biochemical changes in wheat seedlings under water stress. Plant Growth Regulation, 39: 137-141.

Stevens J, Senaratna T, Sivasithamparam K. 2006. Salicylic acid induces salinity tolerance in tomato (Lycopersicon esculentum cv. Roma): associated changes in gas exchange, water relations and membrane stabilization. Plant Growth Regulation, 49:77-83.

Tripathi D, Raikhy G, Kumar D. 2019. Chemical elicitors of systemic acquired resistance-salicylic acid and its functional analogs. Current Plant Biology, 17: 4859.

Yucel Candan N, Heybet Elif H. 2016. Salicylic acid and calcium treatments improves wheat vigor, lipids and phenolics under high salinity. Acta Chimica Slovenica, 63:738-746.

Zarzuelo A, Crespo E. 2002. The medicinal and non-medicinal use of thyme In: StahlBiskup E, Saez F (Eds). Thyme the genus Thymus. 